Check for updates

Cite this: RSC Adv., 2019, 9, 14736

Received 27th March 2019

Accepted 28th April 2019

DOI: 10.1039/c9ra02333j

rsc.li/rsc-advances

\section{Contamination assessment, source apportionment and health risk assessment of heavy metals in paddy soils of Jiulong River Basin, Southeast China}

\begin{abstract}
Huabin Huang, ${ }^{\text {ab }}$ Chengqi Lin, ${ }^{b}$ Ruilian Yu, ${ }^{a}$ Yu Yan, ${ }^{a}$ Gongren Hu (DD *a and Huojin Li ${ }^{\text {b }}$
To trace the sources and evaluate the health risks of heavy metals in paddy soils of Jiulong River Basin, seventyone samples of paddy soils were collected in July 2017. The heavy metals contents were determined using inductively coupled plasma mass spectrometry (ICP-MS) and atomic fluorescence spectrophotometry (AFS). The geo-accumulation index ( $\left.I_{\text {geo }}\right)$ and potential ecological risk index (RI) methods were applied to evaluate the contamination of heavy metals, principal component analysis (PCA) and absolute principal component scores-multiple linear regression (APCS-MLR) were applied to trace the sources, and dose-response model was applied to assess the health risks to the human body. The results indicated that the paddy soils were moderately to heavily polluted by $\mathrm{Cd}$ and slightly polluted by $\mathrm{Hg}, \mathrm{Pb}$, As and $\mathrm{Zn}$. Heavy metals in paddy soils presented considerable to high potential ecological risk, mostly contributed by $\mathrm{Cd}$ and $\mathrm{Hg}$ with contribution rates of $59.4 \%$ and $26.2 \%$, respectively. The heavy metals contaminating paddy soils were derived from natural sources, agricultural activities, industrial discharge, coal combustion and unidentified sources, with source contribution rates of $31.37 \%, 24.87 \%, 19.65 \%, 18.05 \%$ and $6.06 \%$, respectively. The heavy metals in paddy soils presented carcinogenic risks which humans can tolerate and no non-carcinogenic risks. The total noncarcinogenic risks mainly derived from agricultural activities and coal combustion, with contribution rates of $62.16 \%$ and $20.21 \%$, respectively, while the total carcinogenic risks mainly derived from natural sources and industrial discharge, with contribution rates of $51.17 \%$ and $18.98 \%$, respectively.
\end{abstract}

\section{Introduction}

Heavy metals have drawn increasing attention from environmentalists because of their persistence, non-degradability and bioaccumulative characteristic. ${ }^{1}$ The contents of heavy metals in the environment have increased with the rapid economic development in China in the past decades. ${ }^{2}$ The soil can act as both a source and sink for heavy metals. Heavy metals accumulated in soils can cause adverse effects on the human body through direct routes, such as ingestion of soil, inhalation of dust particles and dermal absorption, ${ }^{3}$ and indirect routes, such as the food chain. ${ }^{4}$ Agricultural soil is the basis for the development of agricultural economy. It is of great significance to study the contamination characteristics, source appointment and health risk assessment of heavy metals in agricultural soils.

In the past decades, methods for evaluating heavy metals contamination have been developed by many environmental scientists. ${ }^{5}$ The $I_{\text {geo }}$ method and RI method have been widely used to evaluate the contamination of heavy metals in soils and sediments. ${ }^{6-9}$ It is reported that the combination of $I_{\text {geo }}$ method

${ }^{a}$ College of Chemical Engineering, Fujian Provincial Key Laboratory of Biochemical Technology, Huaqiao University, Xiamen 361021, China. E-mail: grhu@hqu.edu.cn

${ }^{b}$ College of Environment and Public Health, Xiamen Huaxia University, Xiamen 361024, China and RI method can improve the relative accuracy of assessment results by considering the lithology, toxicity and comprehensive effect of heavy metals together. ${ }^{10}$ The dose-response model, recommended by USEPA, has been widely applied to soils to evaluate the human health risk (non-carcinogenic or carcinogenic) due to heavy metals. ${ }^{11}$

It is important to identify the sources of heavy metals for prevention and control of heavy metal pollution. Multivariate statistical analyses have been widely used to trace the sources of heavy metals. ${ }^{12-16}$ Principal component analysis (PCA) is a commonly used tool. Absolute principal component scoresmultiple linear regression (APCS-MLR) has been widely applied for quantitative analysis of pollution sources based on principal component analysis (PCA)..$^{17,18}$

Jiulong River Basin is located in the southwest area of Fujian Province and includes the cities Longyan, Zhangzhou and Xiamen. The safety of the environment around Jiulong River Basin is important to the Western Taiwan Straits Economic Zone. ${ }^{19}$ It is reported that there are more than 3.8 million inhabitants in the basin..$^{20}$ It is also reported that Jiulong River has been polluted by heavy metals due to human activity and rapid development of industry and agriculture..$^{19,21,22}$ Fujian Province is a major rice-producing province in southern China. The Jiulong River Basin plays an important role in the economic development of Fujian Province, contributing about a quarter of 
its GDP. Taking into account the importance of the Jiulong River Basin, it is necessary to study the contamination and effects of heavy metals in paddy soils of this area.

In this study, the contents of eight heavy metals in the paddy soils were analyzed with the following aims: (i) to assess the contamination of heavy metals in the paddy soils; (ii) to trace the potential sources of heavy metals and quantify the contribution rates of the identified sources; (iii) to assess the human health risks and quantify the contribution rates of the identified sources.

\section{Materials and methods}

\subsection{Soil sampling and preparation}

Surface paddy soil samples of depth $0-20 \mathrm{~cm}$ were collected from seventy-one sites in Jiulong River Basin, Southeast China (Fig. 1) in July 2017. Five sub-samples were taken randomly around the area $(10 \mathrm{~m} \times 10 \mathrm{~m})$ of each sample site and mixed into a composite sample. The paddy soils (about $1 \mathrm{~kg}$ per sample) were taken to a clean laboratory and dried. They were then ground with an agate mortar and sieved with a 200 mesh nylon sieve to remove impurities.

\subsection{Determination of heavy metals and quality control}

Approximately $0.2 \mathrm{~g}$ of paddy soil was placed in a $30 \mathrm{~mL}$ Teflon digestion vessel and microwave digested with $2 \mathrm{~mL} \mathrm{HF}, 2 \mathrm{~mL}$ $\mathrm{HCl}$ and $6 \mathrm{~mL} \mathrm{HNO}_{3}$. The contents of heavy metals $\mathrm{Cr}, \mathrm{Ni}, \mathrm{Cu}$, $\mathrm{Zn}, \mathrm{Cd}$, and $\mathrm{Pb}$ were determined by ICP-MS (Agilent 7700x, Agilent Technologies, USA), while for $\mathrm{Hg}$ and As, AFS (AF-640, Ruili Analytical Instrument, China) was used. Blank and soil sample measurements were replicated 3 times. A standard reference (China GBW07405) was analyzed alongside the soil samples for quality control of the analytical method. The recovery rates of all heavy metals were $91.1-108.2 \%$ and the RSD values were all less than $5 \%$.

\subsection{Analytical method}

2.3.1 Contamination assessment method. The $I_{\text {geo }}$ method was proposed by Müller. ${ }^{23}$ It is widely applied to evaluate the pollution level of a single heavy metal in soils and sediments. ${ }^{6,9}$ The value of $I_{\text {geo }}$ was calculated by formula (1):

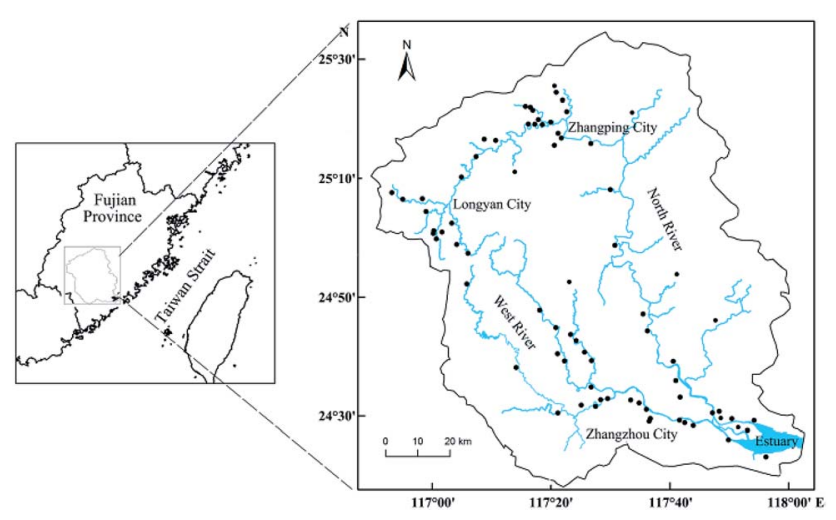

Fig. 1 Sampling locations of paddy soils from Jiulong River Basin.

$$
I_{\text {geo }}=\log _{2}\left[\frac{C_{\mathrm{n}}}{1.5 \times B_{\mathrm{n}}}\right]
$$

where $I_{\text {geo }}$ was the geo-accumulation index of heavy metal $\mathrm{n}, C_{\mathrm{n}}$ was the determined content of heavy metal $n$ in paddy soil and $B_{\mathrm{n}}$ was the background value. The background value in Fujian soils was taken from a previous study. ${ }^{24}$ The classifications of $I_{\text {geo }}$ are listed in Table 1.

The RI method was proposed by Hakanson. ${ }^{25}$ It is widely used to evaluate the potential ecological risk of heavy metals in soils and sediments. ${ }^{\mathbf{8} 26}$ The values of $E_{\mathrm{r}}^{\mathrm{i}}$ and RI were calculated by formulas (2) and (3):

$$
\begin{gathered}
E_{\mathrm{r}}^{\mathrm{i}}=E_{\mathrm{r}}^{\mathrm{i}} \times \frac{C_{\mathrm{i}}}{C_{\mathrm{b}}^{\mathrm{i}}} \\
\mathrm{RI}=\sum_{\mathrm{i}=1}^{\mathrm{i}} E_{\mathrm{r}}^{\mathrm{i}}
\end{gathered}
$$

where $E_{\mathrm{r}}^{\mathrm{i}}$ was the potential ecological risk index of heavy metal i, $C_{\mathrm{i}}$ was the determined content of heavy metal $\mathrm{i}$ in paddy soil and $C_{\mathrm{b}}^{\mathrm{i}}$ was the background value ${ }^{24}$ and $T_{\mathrm{r}}^{\mathrm{i}}$ the biological toxic response factor of heavy metal $i$. The values of $T_{\mathrm{r}}^{\mathrm{i}}$ were as follows: 1 for $\mathrm{Zn}$; 2 for $\mathrm{Cr}$; 5 for $\mathrm{Cu}$, Ni and $\mathrm{Pb}$; 10 for As; 30 for $\mathrm{Cd}$; 40 for $\mathrm{Hg}^{26} \mathrm{RI}$ is the comprehensive index of all heavy metals in this study. The RI standard was adjusted based on the species of examined heavy metal according to $\mathrm{Yu}$ et $a .^{26}$ The classifications of $E_{\mathrm{r}}^{\mathrm{i}}$ and RI are listed in Table 1.

2.3.2 Source apportionment method. The correlation coefficients of heavy metals can be used to indicate the interrelationship between them. It was reported that heavy metals which have significantly positive correlations may have similar sources and migration routes. ${ }^{27}$ PCA is a useful tool for source appointment of heavy metals according the mathematical process of orthogonal transformation. ${ }^{28}$

APCS-MLR was proposed by Thurston and Spengler. ${ }^{29}$ It is widely used for quantitative analysis of identified sources based on PCA. ${ }^{17,18}$ The regression equation is shown as formula (4):

$$
C_{\mathrm{i}}=\left(r_{0}\right)_{\mathrm{i}}+\sum_{\mathrm{k}=1}^{\mathrm{k}}\left(r_{\mathrm{ki}} \times \mathrm{APCS}_{\mathrm{k}}\right)
$$

where $C_{\mathrm{i}}$ was the determined content of the heavy metal i in paddy soils, $\left(r_{0}\right)$ is the constant term of multiple linear regressions, $r$ is the regression coefficient and APCS is the absolute principle component score. The subscript $i$ represents the heavy metal and $\mathrm{k}$ represents the potential source.

2.3.3 Health risk assessment method. Local residents can be exposed to heavy metals in soils through ingestion of soil, inhalation of dust particles and dermal absorption..$^{30}$ The health risk assessment estimates the adverse health effects on a human exposed to chemical contamination. ${ }^{11}$ The average daily intake (ADI), hazard quotients of non-carcinogenic (HI and HQ) and carcinogenic risk (TCR and CR) through three exposure pathways were calculated by formulas (5)-(9). ${ }^{31-33}$

$$
\mathrm{ADI}_{\text {ingestion }}=C_{\text {soil }} \times \frac{\mathrm{IngR}_{\text {soil }} \times \mathrm{EF} \times \mathrm{ED}}{\mathrm{BW} \times \mathrm{AT}} \times 10^{-6}
$$


Table 1 The classifications of geo-accumulation index ( $\left.I_{\text {geo }}\right)$ and potential ecological risk index (RI)

\begin{tabular}{lll}
\hline Index & Category & Degree \\
\hline Geo-accumulation index $\left(I_{\text {geo }}\right)$ & $I_{\text {geo }}<0$ & Non-pollution \\
& $0 \leq I_{\text {geo }}<1$ & Slight pollution \\
& $1 \leq I_{\text {geo }}<2$ & Moderate pollution \\
& $2 \leq I_{\text {geo }}<3$ & Moderate to heavy pollution \\
& $3 \leq I_{\text {geo }}<4$ & Heavy pollution \\
Potential ecological risk index $(\mathrm{RI})$ & $4 \leq I_{\text {geo }}<5$ & Heavy to extreme pollution \\
& $I_{\text {geo }} \geq 5$ & Extreme pollution \\
& $E_{\mathrm{r}}^{\mathrm{i}}<40, \mathrm{RI}<110$ & Low potential ecological risk \\
& $40 \leq E_{\mathrm{r}}^{\mathrm{i}}<80,110 \leq \mathrm{RI}<220$ & Moderate potential ecological risk \\
& $80 \leq E_{\mathrm{r}}^{\mathrm{i}}<160,220 \leq \mathrm{RI}<440$ & Considerable potential ecological risk \\
& $160 \leq E_{\mathrm{r}}^{\mathrm{i}}<320, \mathrm{RI} \geq 440$ & High potential ecological risk \\
& $E_{\mathrm{r}}^{\mathrm{i}} \geq 320$ & Extreme potential ecological risk
\end{tabular}

$$
\begin{gathered}
\mathrm{ADI}_{\text {inhalation }}=C_{\text {soil }} \times \frac{\mathrm{InhR}_{\text {soi }} \times \mathrm{EF} \times \mathrm{ED}}{\mathrm{PEF} \times \mathrm{BW} \times \mathrm{AT}} \\
\mathrm{ADI}_{\text {dermal }}=C_{\text {soil }} \times \frac{\mathrm{SA} \times \mathrm{AF} \times \mathrm{ABS} \times \mathrm{EF} \times \mathrm{ED}}{\mathrm{BW} \times \mathrm{AT}} \times 10^{-6} \\
\mathrm{HI}=\sum_{\mathrm{i}=1}^{\mathrm{i}} \mathrm{HQ}_{\mathrm{i}}=\sum_{\mathrm{i}=1}^{\mathrm{i}} \frac{\mathrm{ADI}_{\mathrm{i}}}{\mathrm{RfD}_{\mathrm{i}}} \\
\mathrm{TCR}=\sum_{\mathrm{i}=1}^{\mathrm{i}} \mathrm{CR}_{\mathrm{i}}=\sum_{\mathrm{i}=1}^{\mathrm{i}}\left(\mathrm{ADI}_{\mathrm{i}} \times \mathrm{SF}_{\mathrm{i}}\right)
\end{gathered}
$$

where $\mathrm{AD}_{\text {Iingestion, }} \mathrm{AD}_{\text {Iinhalation }}$ and $\mathrm{AD}_{\text {Idermal }}$ were the average daily intakes through the three exposure pathways, IngR $\mathrm{R}_{\text {soil }}$ was the ingestion rate of soil, $\mathrm{InhR}_{\text {soil }}$ was the inhalation rate of soil and $C_{\text {soil }}$ was the determined content of the heavy metal $\mathrm{n}$ in paddy soils. EF was the exposure frequency, ED was the exposure duration, BW was the average body weight, AT was the average exposure time, PEF was the emission factor of soil, SA was the area of exposed skin, AF was the adherence factor of skin and ABS was dermal absorption factor. HI was the total hazard index of several heavy metals; HQ was the hazard quotient of a single heavy metal. When the value of HI or HQ is lower than 1, there is no non-carcinogenic risk. RfD was the reference dose of non-carcinogenic heavy metals, TCR was the total cancer risk of several heavy metals, CR was the carcinogenic risk of a single heavy metal and SF was the carcinogenicity slope factor. When $10^{-6}<$ TCR (or CR) $<10^{-4}$, there is carcinogenic risk which humans can tolerate, whereas when $10^{-4}<$ TCR (or CR), there is unacceptable carcinogenic risk. The selection of exposure parameters can affect the accuracy of the results. The parameters used in formulas (5)-(9) were taken from highly cited studies conducted in China and are listed in Tables 2 and 3.

\section{Results and discussion}

\subsection{Contents and spatial distribution of heavy metals}

The statistics parameters of heavy metals are listed in Table 4. The mean contents of heavy metals were Cr: $61.80 \pm 21.79, \mathrm{Ni}$ :

\begin{tabular}{|c|c|c|c|c|c|c|}
\hline Parameter & Interpretation & Units & Adult male & Adult female & Children & Reference \\
\hline $\mathrm{EF}$ & Exposure frequency & Day per year & 345 & 345 & 345 & \\
\hline ED & Exposure duration & Year & 70 & 70 & 18 & \\
\hline BW & Body weight & $\mathrm{kg}$ & 67.55 & 57.59 & 29.30 & \\
\hline SA & Exposed skin area & $\mathrm{m}^{2}$ & 0.169 & 0.153 & 0.086 & \\
\hline $\mathrm{AF}$ & Adherence factor & $\mathrm{mg}\left(\mathrm{cm}^{-2}\right.$ day $\left.^{-1}\right)$ & 0.49 & 0.49 & 0.65 & \\
\hline $\mathrm{ABS}(\mathrm{Cd})$ & Absorption factor & & 0.14 & 0.14 & 0.14 & \\
\hline $\mathrm{ABS}(\mathrm{Cr})$ & & & 0.04 & 0.04 & 0.04 & \\
\hline ABS(As) & & & 0.03 & 0.03 & 0.03 & \\
\hline $\mathrm{ABS}(\mathrm{Hg})$ & & & 0.05 & 0.05 & 0.05 & \\
\hline InhR & Inhalation rate & $\mathrm{m}^{3} \mathrm{~d}^{-1}$ & 16.57 & 12.80 & 7.63 & 34 \\
\hline PEF & Particle emission factor & $\mathrm{m}^{3} \mathrm{~kg}^{-1}$ & $1.36 \times 10^{9}$ & $1.36 \times 10^{9}$ & $1.36 \times 10^{9}$ & \\
\hline
\end{tabular}
$12.85 \pm 5.17, \mathrm{Cu}: 35.05 \pm 15.56, \mathrm{Zn:} 151.71 \pm 63.52$, As: $10.22 \pm$ 2.22, Cd: $0.34 \pm 0.16, \mathrm{~Pb}: 72.29 \pm 27.64$, and $\mathrm{Hg}: 0.17 \pm 0.04 \mathrm{mg}$

Table 2 The parameters used in the calculation of average daily intake (ADI) 
Table 3 The reference doses (RfD) and slope factors (SF) used in health risk assessment ${ }^{a}$

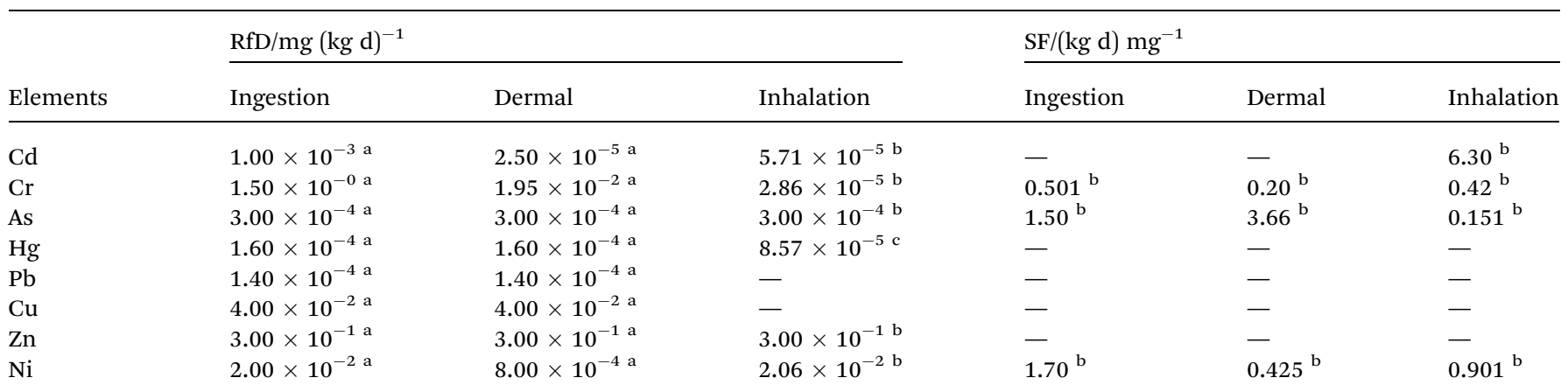

${ }^{a}$ The superscripts a, b and c indicate data cited from Li et al., ${ }^{11}$ Cao et al., ${ }^{35}$ and Chen et al., ${ }^{34}$ respectively.

Table 4 Statistics parameters $\left(\mathrm{mg} \mathrm{kg}^{-1}\right)$ of heavy metals in paddy soils of Jiulong River Basin

\begin{tabular}{lllllllll}
\hline Element & $\mathrm{Cr}$ & $\mathrm{Ni}$ & $\mathrm{Cu}$ & $\mathrm{Zn}$ & $\mathrm{As}$ & $\mathrm{Cd}$ & $\mathrm{Pb}$ & $\mathrm{Hg}$ \\
Max & 110.93 & 25.52 & 81.32 & 437.90 & 16.88 & 0.92 & 168.10 & 0.26 \\
Min & 41.36 & 5.85 & 19.32 & 83.16 & 6.21 & 0.12 & 40.16 & 0.11 \\
Mean & 61.80 & 12.85 & 35.05 & 151.71 & 10.22 & 0.34 & 72.29 & 0.17 \\
$\mathrm{SD}$ & 21.79 & 5.17 & 15.56 & 63.52 & 2.22 & 0.16 & 27.64 & 0.04 \\
$\mathrm{CV}$ & 0.35 & 0.40 & 0.44 & 0.42 & 0.22 & 0.48 & 0.38 & 0.24 \\
Background & 41.30 & 13.50 & 21.60 & 82.70 & 5.78 & 0.05 & 34.90 & 0.08
\end{tabular}

$\mathrm{kg}^{-1}$. The background values of heavy metals in Fujian soils were taken from literature. ${ }^{24}$ In this study, the mean contents of heavy metals in paddy soils were higher than the background values. Compared to the limit values of Chinese environmental quality standards for soils (GB15618-2018), the excess rates of $\mathrm{Cu}, \mathrm{Zn}$ and $\mathrm{Cd}$ were $14.1 \%, 16.9 \%$ and $49.3 \%$, respectively. The coefficient variances of all heavy metals were between 0.2 and 0.5 , which indicated that all the heavy metals showed moderate variability. ${ }^{36}$

Kriging interpolation was used to analyze the spatial distribution trend of heavy metals in paddy soils and the results are shown in Fig. 2. Higher contents of $\mathrm{Cr}, \mathrm{Ni}, \mathrm{Cu}, \mathrm{Zn}$ and $\mathrm{Cd}$ appeared in North River (Longyan City); higher contents of $\mathrm{Pb}$ appeared in West River; higher contents of $\mathrm{Hg}$ and As appeared in Estuary. The spatial distributions of heavy metals may be the consequence of various sources of pollution, but more information about the pollution sources needs to be explored in depth using different statistical analysis.

\subsection{Contamination assessment of heavy metals}

The values of $I_{\text {geo }}$ and $E_{\mathrm{r}}$ calculated by formulas (1) and (2) are shown in Fig. 3. The mean $I_{\text {geo }}$ values followed a sequence of $\mathrm{Cd}$ $>\mathrm{Hg}>\mathrm{Pb}>\mathrm{Cu}>\mathrm{As}>\mathrm{Co}>\mathrm{Zn}>\mathrm{Cr}>\mathrm{V}>\mathrm{Ni}$. The mean $I_{\text {geo }}$ of $\mathrm{Cd}$ was 1.9 , with $35.2 \%$ of the samples presenting moderate to heavy pollution $\left(2 \leq I_{\text {geo }}<3\right.$ ) and $54.9 \%$ of the samples presenting moderate pollution $\left(1 \leq I_{\text {geo }}<2\right)$. The mean $I_{\text {geo }}$ of $\mathrm{Hg}$ was 0.42 , with $7.0 \%$ of the samples presenting moderate pollution $\left(1 \leq I_{\text {geo }}<2\right)$ and $88.7 \%$ of the samples presenting slight pollution $\left(0 \leq I_{\text {geo }}<1\right)$. The mean $I_{\text {geo }}$ of $\mathrm{Pb}$ was 0.38 , with $11.3 \%$ of the samples presenting moderate pollution $\left(1 \leq I_{\text {geo }}<\right.$ 2 ) and $70.4 \%$ of the samples presenting slight pollution $\left(0 \leq I_{\text {geo }}\right.$ $<1$ ). The mean $I_{\text {geo }}$ of As and $\mathrm{Zn}$ were 0.21 and 0.19 , respectively, with most of the samples presenting slight pollution $\left(0 \leq I_{\text {geo }}<\right.$ 1). The mean $I_{\text {geo }}$ of $\mathrm{Cu}, \mathrm{Cr}$ and Ni were $0.00,-0.08$ and -0.77 , respectively, with most of the samples presenting non-pollution $\left(I_{\text {geo }}<0\right)$.

The mean $E_{\mathrm{r}}$ values followed a sequence of $\mathrm{Cd}>\mathrm{Hg}>\mathrm{As}>\mathrm{Pb}>$ $\mathrm{Cu}>\mathrm{Co}>\mathrm{Ni}>\mathrm{Cr}>\mathrm{V}>\mathrm{Zn}$. The mean $E_{\mathrm{r}}$ of $\mathrm{Cd}$ was 187.6, with $14.1 \%$ of the samples presenting extreme risk, $35.2 \%$ of the samples presenting high risk and $46.5 \%$ of the samples presenting considerable risk. The mean $E_{\mathrm{r}}$ of $\mathrm{Hg}$ was 82.6 , with $42.3 \%$ of the samples presenting considerable risk and $57.7 \%$ of the samples presenting moderate risk. All the $E_{\mathrm{r}}$ of $\mathrm{As}, \mathrm{Pb}, \mathrm{Cu}, \mathrm{Ni}, \mathrm{Cr}$ and $\mathrm{Zn}$ were lower than 40, presenting low risk. The comprehensive potential ecological risk index (RI) of eight heavy metals ranged from 169.0 to 688.9 with the mean value of 316.0 . $12.7 \%$ of the samples presented high potential ecological risk $(\mathrm{RI} \geq 440)$ and $78.9 \%$ of the samples presented considerable potential ecological risk (220 $\left.\leq E_{\mathrm{r}}<440\right)$. The contribution rates of different heavy metals to the comprehensive potential ecological risk index were calculated and it was found that the comprehensive potential ecological risk was mostly contributed by $\mathrm{Cd}$ and $\mathrm{Hg}$ with contribution rates of $59.4 \%$ and $26.2 \%$, respectively.

The assessment results of $I_{\text {geo }}$ method and RI method were basically consistent, but some differences still exist. For example, $\mathrm{Pb}$ was assessed to be slight to moderate pollution by $I_{\text {geo }}$, while it was assessed to be low risk by RI. Hg was assessed to be slight to moderate pollution by $I_{\text {geo }}$, while it was assessed to be moderate to considerable risk by RI. These results may be attributed to the different toxicities of heavy metals. ${ }^{37}$ The $I_{\text {geo }}$ method focused on the lithology and a single heavy metal, while the RI method considered the toxicities and comprehensive effects of more than one heavy metal. The combination of $I_{\text {geo }}$ method and RI method can make the evaluation results more accurate by considering the lithology, toxicity and comprehensive effect of heavy metals together.

\subsection{Source apportionment of heavy metals}

The Pearson's correlations matrix between the contents of heavy metals is listed in Table 5. There were significant correlations between $\mathrm{Cr}, \mathrm{Ni}, \mathrm{Cu}$, and $\mathrm{Zn}$ and significant correlations between $\mathrm{Cd}, \mathrm{Zn}$ and $\mathrm{Pb}$. These results indicated that each group may have similar sources. 


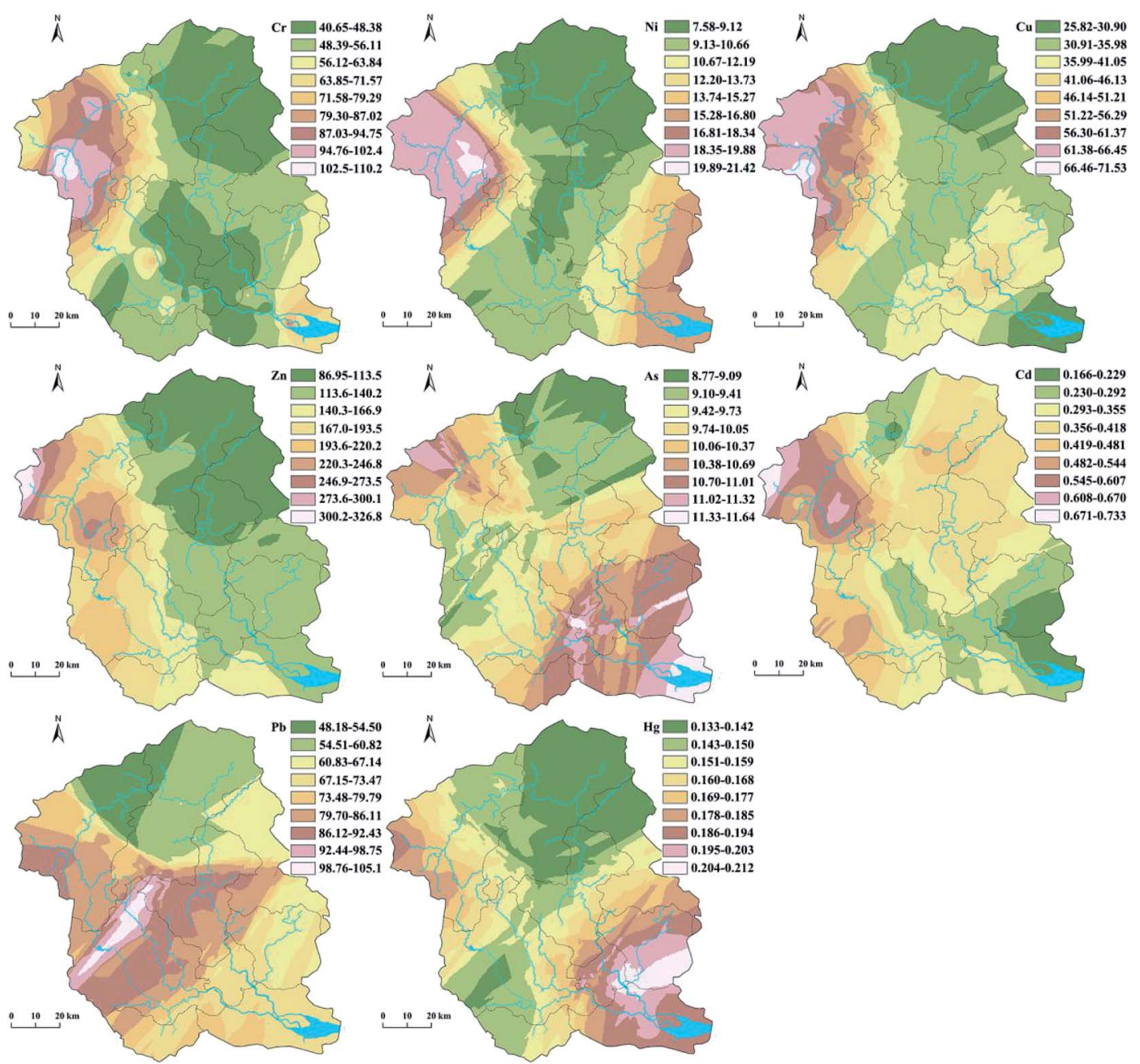

Fig. 2 Spatial distributions of heavy metals in paddy soils of Jiulong River Basin.
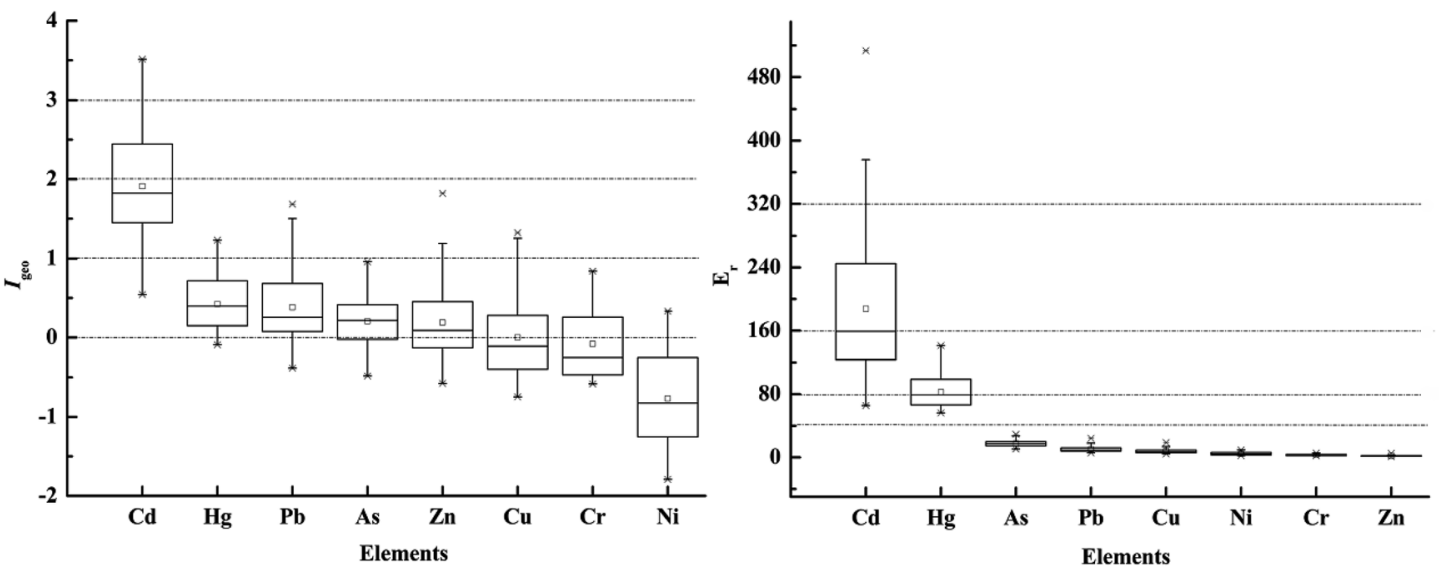

Fig. 3 Results of geo-accumulation index $\left(I_{\text {geo }}\right)$ and potential ecological risk index $\left(E_{r}\right)$ evaluations of heavy metals in paddy soils.

For further analysis, PCA was used to trace the sources of heavy metals and the results are listed in Table 6. The values of heavy metal content were suitable for PCA analysis, according to the values of KMO (0.643) and Bartlett's test (0.000). As shown in Table 6, four principal components, which comprise $83.55 \%$ of the total variance, were extracted and they each explain $40.09 \%$, $18.78 \%, 13.95$ and $10.73 \%$ of the total variance. PC1 is heavily weighted by $\mathrm{Cr}$, Ni and $\mathrm{Cu}$, which indicated that these elements may be derived from the same sources. The contents of $\mathrm{Cr}, \mathrm{Ni}$ and $\mathrm{Cu}$ were more similar to the background values of Fujian 
Table 5 Pearson's correlations matrix between heavy metal concentrations $^{a}$

\begin{tabular}{llllllll}
\hline $\mathrm{Cr}$ & $\mathrm{Ni}$ & $\mathrm{Cu}$ & $\mathrm{Zn}$ & $\mathrm{As}$ & $\mathrm{Cd}$ & $\mathrm{Pb}$ & $\mathrm{Hg}$ \\
\hline
\end{tabular}

Cr 1

Ni $0.801^{* *} 1$

$\mathrm{Cu} \quad 0.562 * * \quad 0.476 * * \quad 1$

Zn $\quad 0.385^{* *} \quad 0.369^{* *} \quad 0.531^{* *} \quad 1$

As $\begin{array}{lllll}0.022 & 0.196 & 0.168 & 0.283^{*} & 1\end{array}$

$\begin{array}{lllllll}\text { Cd } & 0.393 * * & 0.302 * & 0.438 * * & 0.783 * * & 0.229 & 1\end{array}$

$\begin{array}{llllllll}\mathrm{Pb} & -0.001 & 0.058 & -0.035 & 0.468^{* *} & 0.133 & 0.487^{* *} & 1\end{array}$

$\begin{array}{lllllllll}\mathrm{Hg} & -0.036 & 0.208 & 0.107 & 0.081 & 0.12 & -0.052 & 0.067 & 1\end{array}$

$a * *$ significant correlation $(p<0.01)$; *significant correlation $(p<0.05)$.

Table 6 Rotated component matrix of principal component analysis for heavy metals

\begin{tabular}{lrrrr}
\hline & \multicolumn{3}{l}{ Principal components } & \\
\cline { 2 - 5 } Element & PC1 & PC2 & \multicolumn{1}{c}{ PC3 } & \multicolumn{1}{c}{ PC4 } \\
\hline $\mathrm{Cr}$ & $\mathbf{0 . 9 2 0}$ & 0.097 & -0.104 & -0.079 \\
$\mathrm{Ni}$ & $\mathbf{0 . 8 5 5}$ & 0.072 & 0.058 & 0.225 \\
$\mathrm{Cu}$ & $\mathbf{0 . 7 5 8}$ & 0.171 & 0.196 & -0.016 \\
$\mathrm{Zn}$ & 0.426 & $\mathbf{0 . 7 6 9}$ & 0.225 & -0.007 \\
$\mathrm{As}$ & 0.060 & 0.122 & $\mathbf{0 . 9 6 6}$ & 0.076 \\
$\mathrm{Cd}$ & 0.372 & $\mathbf{0 . 8 0 3}$ & 0.153 & -0.163 \\
$\mathrm{~Pb}$ & -0.167 & $\mathbf{0 . 8 6 8}$ & -0.048 & 0.147 \\
$\mathrm{Hg}$ & 0.072 & 0.016 & 0.073 & $\mathbf{0 . 9 7 4}$ \\
\hline
\end{tabular}

source, which indicated that PC1 may be related to natural sources. PC2 is heavily weighted by $\mathrm{Zn}, \mathrm{Cd}$ and $\mathrm{Pb}$, which indicated that these elements may be derived from the same sources. $\mathrm{Zn}, \mathrm{Cd}$ and $\mathrm{Pb}$ are commonly found in fertilizers and pesticides and Cd can generally be used as a marker element for agricultural activities, such as pesticides and chemical fertilizers. ${ }^{38,39} \mathrm{~Pb}$ may also be derived from vehicle exhaust sources. ${ }^{40}$ However, it has been reported that vehicle exhaust was not the main source of $\mathrm{Pb}$ in the sediments of Jiulong River Basin. ${ }^{19}$ Jiulong River Basin is an agricultural river network. ${ }^{41}$ The research of $\mathrm{Li}^{42}$ indicated that the large-scale use of pesticides and fertilizers is one of the main causes of water pollution in the Jiulong River Basin. Furthermore, Zhang et al. ${ }^{21}$ indicated that the contents of $\mathrm{Cd}, \mathrm{Pb}$ and $\mathrm{Zn}$ in the water of Jiulong River were mainly affected by geochemistry and agricultural activities. Jiulong River is the main source of agricultural water for the basin. Based on the above discussion, PC2 may be related to agricultural activities. PC3 is heavily weighted by As. It has been reported that As may be related to industrial activities such as industrial discharge and sewage sludge. ${ }^{43}$ It was reported that Xiamen City, located in the Jiulong River estuary area, has the third highest number of heavy metal enterprises. ${ }^{44}$ There are paper mills, pharmaceutical factories, chemical plants and metal processing factories located in the downstream and estuary of Jiulong River. The discharges from these industrial factories could contribute to As pollution in paddy soils. In this study, the higher concentrations of As appeared in the downstream and estuary watershed areas (Fig. 2). Therefore, PC3 may be related to industrial discharges. PC4 is heavily weighted by Hg. It was reported that coal combustion is an important source of $\mathrm{Hg}$ emission in China. ${ }^{45}$ According to previous research, coal combustion is also an important source of $\mathrm{Hg}$ in the sediments of Jiulong River. ${ }^{46}$ In this study, the higher concentrations of $\mathrm{Hg}$ appeared in the estuary watershed (Fig. 2), where a coal-fired power plant was located. Therefore, PC4 may be related to coal combustion.

Based on the results of PCA, APCS-MLR was used to quantify the contribution rates of each heavy metal source and the results are shown in Fig. 4. Natural sources contributed most to $\mathrm{Cr}, \mathrm{Ni}$ and $\mathrm{Cu}$, with contribution rates of $68.74 \%, 60.23 \%$ and $60.76 \%$, respectively. Agricultural activities contributed most to $\mathrm{Zn}, \mathrm{Cd}$ and $\mathrm{Pb}$, with contribution rates of $47.43 \%, 54.63 \%$ and $66.33 \%$, respectively. Industrial discharge contributed most to As with a contribution rate of $74.51 \%$ and coal combustion contributed most to $\mathrm{Hg}$ with a contribution rate of $89.03 \%$. The unidentified sources may be a mixture of traffic sources, domestic sewage and other potential sources.

\subsection{Health risk assessment of heavy metals}

Heavy metals contaminating the soil can pose health risks to the human body through several pathways. One pathway is through the food chain (soil-crop-human body). There have been several previous studies of the health risks of heavy metals in rice grown in Fujian Province. ${ }^{47-49}$ The results indicated that the accumulation of $\mathrm{Cd}$ and $\mathrm{Pb}$ in rice posed potential health risks to consumers of some areas in Fujian Province. The other pathway is through direct exposure. Local residents can be exposed to heavy metals in soils through ingestion of soil, inhalation of dust particles and dermal absorption.

In this study, the objective is to evaluate the health risks of heavy metals through direct exposure pathways. The noncarcinogenic hazard index and carcinogenic risk index were calculated by formulas (5)-(9) and the results are presented in Table 7. The values of non-carcinogenic hazard index were all lower than 1, suggesting no non-carcinogenic risks to the

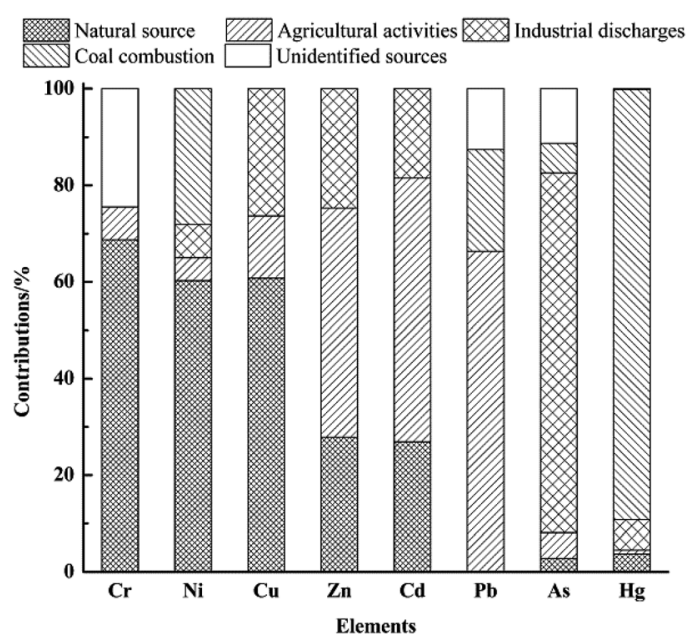

Fig. 4 Contributions of each source to heavy metals in paddy soils. 
Table 7 Health risks of heavy metals to populations through different pathways

\begin{tabular}{|c|c|c|c|c|c|c|}
\hline & \multicolumn{3}{|c|}{ Non-carcinogenic hazard index } & \multicolumn{3}{|l|}{ Carcinogenic risk index } \\
\hline & Adult male & Adult female & Children & Adult male & Adult female & Children \\
\hline $\mathrm{Ni}$ & $(2.31 \pm 0.93) \times 10^{-4}$ & $(2.71 \pm 1.09) \times 10^{-4}$ & $(5.08 \pm 2.04) \times 10^{-4}$ & $(7.65 \pm 3.07) \times 10^{-6}$ & $(8.97 \pm 3.61) \times 10^{-6}$ & $(4.35 \pm 1.75) \times 10^{-6}$ \\
\hline $\mathrm{Cu}$ & $(3.07 \pm 1.36) \times 10^{-4}$ & $(3.60 \pm 1.60) \times 10^{-4}$ & $(6.79 \pm 3.01) \times 10^{-4}$ & & & \\
\hline $\mathrm{Zn}$ & $(1.77 \pm 0.74) \times 10^{-4}$ & $(2.08 \pm 0.87) \times 10^{-4}$ & $(3.92 \pm 1.64) \times 10^{-4}$ & & & \\
\hline $\mathrm{Pb}$ & $(1.81 \pm 0.69) \times 10^{-1}$ & $(2.12 \pm 0.81) \times 10^{-1}$ & $(4.00 \pm 1.53) \times 10^{-1}$ & & & \\
\hline $\mathrm{Hg}$ & $(3.66 \pm 0.89) \times 10^{-4}$ & $(4.30 \pm 1.04) \times 10^{-4}$ & $(8.10 \pm 1.97) \times 10^{-4}$ & & & \\
\hline Total & $(1.94 \pm 0.69) \times 10^{-1}$ & $(2.28 \pm 0.82) \times 10^{-1}$ & $(4.29 \pm 1.54) \times 10^{-1}$ & $(2.38 \pm 0.68) \times 10^{-5}$ & $(2.80 \pm 0.79) \times 10^{-5}$ & $(1.36 \pm 0.39) \times 10^{-5}$ \\
\hline
\end{tabular}

\section{Carcinogenic risks}

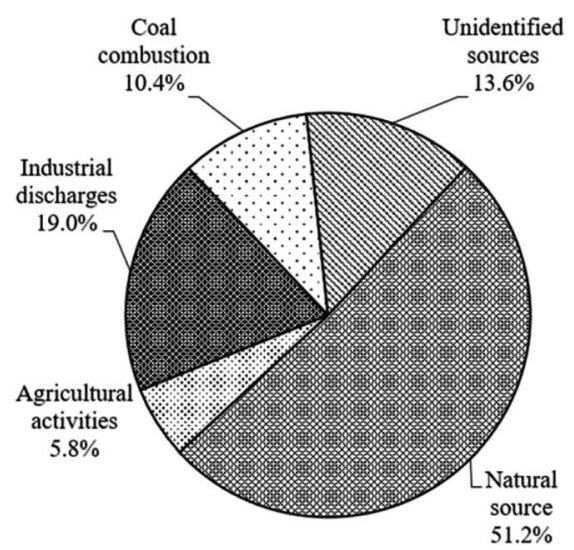

\section{Non-carcinogenic risks}

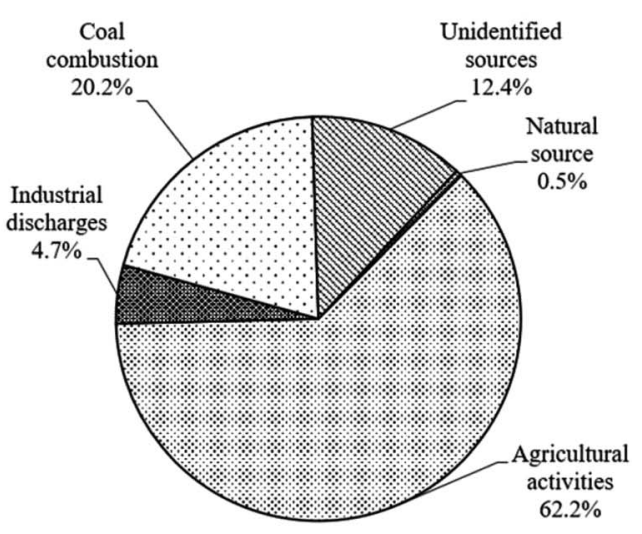

Fig. 5 Contributions of identified sources to the health risks of adult males.

human body. The values of carcinogenic risk index were all in the range of $10^{-6}$ to $10^{-4}$ which suggest carcinogenic risks that humans can tolerate. The total hazard index (HI) of eight heavy metals followed a sequence of children $(0.429 \pm 0.154)>$ adult female $(0.228 \pm 0.082)>$ adult male $(0.194 \pm 0.069)$. This result might be the reason that children are more sensitive to environmental pollutants which lead to higher non-carcinogenic risks. ${ }^{28,50}$

The contribution rates of single metals to the total noncarcinogenic and total carcinogenic risks were calculated. According to the results, the total non-carcinogenic risks were comprised mostly by $\mathrm{Pb}$ and As with contribution rates of $93.04 \%$ and $6.14 \%$, respectively. The total carcinogenic risks were mostly contributed by $\mathrm{Cr}, \mathrm{Ni}$ and As with contribution rates of $45.44 \%, 32.06 \%$ and $22.50 \%$, respectively.

Combining the results of APCS-MLR and the health risk assessment, the contributions of the identified sources to health risks of adult males were calculated and the results are shown in Fig. 5. The total non-carcinogenic risks were mainly derived from agricultural activities and coal combustion with contribution rates of $62.16 \%$ and $20.21 \%$, respectively, while the total carcinogenic risks were mainly derived from natural sources and industrial discharge with contribution rates of $51.17 \%$ and $18.98 \%$, respectively.

\section{Conclusions}

In this study, the concentrations of heavy metals in the paddy soils of Jiulong River Basin were analyzed to investigate the contamination, source apportionment and human health risks of heavy metals.

The results of this study showed that the mean contents of $\mathrm{Cr}, \mathrm{Cu}, \mathrm{Zn}, \mathrm{As}, \mathrm{Cd}, \mathrm{Pb}$ and $\mathrm{Hg}$ were higher than the background value of Fujian soil and the contents of all the heavy metals showed moderate variability.

The $I_{\text {geo }}$ method indicated that the paddy soils were moderately to heavily polluted by $\mathrm{Cd}$ and slightly polluted by $\mathrm{Hg}, \mathrm{Pb}, \mathrm{As}$ and $\mathrm{Zn}$. The results of the RI method indicated that heavy metals in paddy soils presented considerable to high potential ecological risk, mostly contributed by $\mathrm{Cd}$ and $\mathrm{Hg}$ with contribution rates of $59.4 \%$ and $26.2 \%$, respectively.

The source apportionment of heavy metals indicated that natural sources contributed most to $\mathrm{Cr}$, $\mathrm{Ni}$ and $\mathrm{Cu}$, with contribution rates of $68.74 \%, 60.23 \%$ and $60.76 \%$, respectively. Agricultural activities contributed most to $\mathrm{Zn}, \mathrm{Cd}$ and $\mathrm{Pb}$, with contribution rates of $47.43 \%, 54.63 \%$ and $66.33 \%$, respectively. Industrial discharge contributed most to As with a contribution rate of $74.51 \%$ and coal combustion contributed most to $\mathrm{Hg}$ with the rate of $89.03 \%$. 
The results of the health risk assessment indicated that heavy metals in paddy soils presented no non-carcinogenic risks, with all the HI values lower than 1 . There were carcinogenic risks which humans can tolerate, with CR values falling in the range of $10^{-6}$ to $10^{-4}$. According to the results of APCS-MLR and the health risk assessment, the total non-carcinogenic risks mainly derived from agricultural activities and coal combustion, with contribution rates of $62.16 \%$ and $20.21 \%$, respectively, while the total carcinogenic risks mainly derived from natural sources and industrial discharge, with contribution rates of $51.17 \%$ and $18.98 \%$, respectively.

These results can provide a reference for the prevention and control of heavy metals contamination.

\section{Conflicts of interest}

There are no conflicts to declare.

\section{Acknowledgements}

This research was supported by the National Natural Science Foundation of China (21777049), Natural Science Foundation of Fujian Province (2011J01273), and the Opening Fund of the State Key Laboratory of Environmental Geochemistry (SKLEG2016901).

\section{References}

1 X. L. Wang, L. Zhang, Z. H. Zhao and Y. J. Cai, Sci. Total Environ., 2018, 634, 158-169.

2 F. J. Zhao, Y. Ma, Y. G. Zhu, Z. Tang and S. P. Mcgrath, Environ. Sci. Technol., 2015, 49(2), 750.

3 N. Soltani, B. Keshavarzi, F. Moore, T. Tavakol, A. R. Lahijanzadeh, N. Jaafarzadeh and M. Kermani, Sci. Total Environ., 2015, 505, 712-723.

4 A. Bhatia, S. Singh and A. Kumar, Water Environ. Res., 2015, 87(11), 2027-2034.

5 Y. J. Wang, T. L. Wu, D. M. Zhou and H. M. Chen, J. AgroEnviron. Sci., 2017, 36(12), 2365-2378.

6 U. Aiman, A. Mahmood, S. Waheed and R. N. Malik, Chemosphere, 2016, 151, 2229-2237.

7 M. Gąsiorek, J. Kowalska, R. Mazurek and M. Pająk, Chemosphere, 2017, 179, 148-158.

8 S. Islam, K. Ahmed and S. Masunaga, Sci. Total Environ., 2015, 512-513, 94-102.

9 P. I. Omwene, M. S. Öncel, M. Çelen and M. Kobya, Chemosphere, 2018, 159, 782-792.

10 J. M. Trujillo-González, M. A. Torres-Mora, S. Keesstra, E. C. Brevik and R. Jiménez-Ballesta, Sci. Total Environ., 2016, 553, 636-642.

11 Z. Y. Li, Z. W. Ma, T. J. van der Kuijp, Z. W. Yuan and L. Huang, Sci. Total Environ., 2014, 468, 843-853.

12 K. R. Bindu, P. M. Deepulal, T. R. Gireeshkumar and N. Chandramohanakumar, Environ. Monit. Assess., 2015, 187(8), 1-23.

13 Y. Chai, G. Jia, S. L. Chai, J. Cai, L. F. Xue and Q. W. Zhang, Chemosphere, 2015, 134, 67-75.
14 D. Y. Hou, D. O'Connor, P. Nathanail, L. Tian L and Y. Ma, Environ. Pollut., 2017, 231, 1188-1200.

15 G. Tepanosyan, L. Sahakyan, O. Belyaeva, N. Maghakyan and A. Saghatelyan, Chemosphere, 2017, 184, 1230-1240.

16 S. Venkatramanan, S. Y. Chung, T. Ramkumar and S. Selvam, Environ. Monit. Assess., 2015, 187(8), 1-16.

17 M. H. Gholizadeh, A. Melesse and L. Reddi, Sci. Total Environ., 2016, 566, 1552-1567.

18 K. P. Singh, A. Malik, R. Kumar, P. Saxena and S. Sinha, Environ. Monit. Assess., 2008, 136, 183-196.

19 C. Q. Lin, R. L. Yu, G. R. Hu, Q. L. Yang and X. M. Wang, Environ. Pollut., 2016, 218, 644-650.

20 N. W. Chen, J. Z. Wu, X. P. Zhou, Z. H. Chen and T. Lu, Agric., Ecosyst. Environ., 2015, 208, 37-47.

21 L. Zhang, S. H. Qi, C. K. Qu, H. X. Liu, W. W. Chen, F. Li, T. $\mathrm{Hu}$ and H. F. Huang, China Environ. Sci., 2014, 34(8), 2133-2139.

22 Z. Zhang, Y. L. Cao, C. Cai and Z. Y. Huang, J. Saf. Environ., 2013, 13(1), 129-133.

23 G. Müller, GeoJournal, 1969, 2(3), 108-118.

24 Z. J. Chen, C. X. Chen, Y. Q. Liu, Y. D. Wu, S. K. Yang and C. Y. Lu, Chin. J. Environ. Sci., 1992, 13, 70-75.

25 L. Hakanson, Water Res., 1980, 14(8), 975-1001.

26 R. L. Yu, G. R. Hu, C. Q. Lin, Q. L. Yang, C. C. Zhang and X. M. Wang, Appl. Geochem., 2017, 83, 41-49.

27 X. S. Luo, Y. Xue, Y. L. Wang, L. Cang, B. Xu and J. Ding, Chemosphere, 2015, 127, 152-157.

28 W. C. Ma, L. Y. Tai, Z. Qiao, L. Zhong, Z. Wang, K. X. Fu and G. Y. Chen, Sci. Total Environ., 2018, 631-632, 348-357.

29 G. D. Thurston and J. D. Spengler, Atmos. Environ., 1985, 19(1), 9-25.

30 C. S. Qu, K. Sun, S. R. Wang, L. Huang and J. Bi, Hum. Ecol. Risk Assess. Int. J, 2012, 4, 733-750.

31 USEPA, Guidelines for the health risk assessment of chemical mixtures, US Environmental Protection Agency, Washington, DC, 1986, EPA/630/R-98/002.

32 USEPA, Risk assessment guidance for Superfund. Human health evaluation manual, (part A), Office of Emergency and Remedial Response, Washington, DC, 1989, vol. 1, EPA/ 540/1-89/002.

33 USEPA, Supplemental guidance for developing soil screening levels for Superfund sites, Solid Waste and Emergency Response, Washington, DC, 2002, OSWER9355.4-24.

34 H. Y. Chen, Y. G. Teng, S. J. Lu, Y. Y. Wang, J. Wu and J. S. Wang, Chemosphere, 2016, 144, 1002-1011.

35 S. Z. Cao, X. L. Duan, X. G. Zhao, J. Ma, T. Dong, N. Huang, C. Y. Sun, B. He and F. S. Wei, Sci. Total Environ., 2014, 472, 1001-1009.

36 P. Phil-Eze, J. Geogr. Reg. Plan., 2010, 3(7), 177-184.

37 F. M. Kusin, M. S. Rahman, Z. Madzin, S. Jusop, F. MohamatYusuff, M. Ariffin and Z. Ms, Environ. Sci. Pollut. Res. Int., 2017, 24, 2306-2321.

38 C. W. Gray, R. G. Mclaren and A. H. C. Roberts, Nutrient Cycl. Agroecosyst., 1999, 54(3), 267-277.

39 J. S. Lv, Y. Liu, Z. L. Zhang, J. R. Dai, B. Dai and Y. C. Zhu, J. Soils Sediments, 2015, 15(1), 163-178. 
40 A. Facchinelli, E. Sacchi and L. Mallen, Environ. Pollut., 2001, 114, 313-324.

41 N. W. Chen, J. Z. Wu, Z. H. Chen, T. Lu and L. J. Wang, Agric., Ecosyst. Environ., 2014, 189, 1-10.

42 J. J. Li, Subtropical Soil and Water Conservation, 2017, 29(1), 7-11.

43 S. Charlesworth, M. Everett, R. McCarthy, A. OrdSQez and E. de Miguel, Environ. Int., 2003, 29, 563-573.

44 R. F. Ma, B. Q. Zhou, J. F. Liu and J. B. Zhang, Pollut. Control Technol., 2016, 29(1), 19-22.

45 Y. Z. Sun, Y. Chen, H. Lan, L. Y. Liu and L. Fang, Environ. Chem., 2013, 32(6), 937-942.
46 S. Wang, G. R. Hu, R. L. Yu, W. H. Yu and C. F. Zhou, Res. J. Environ. Sci., 2014, 27(10), 1110-1118.

47 J. F. Tu, L. Y. Liu, Q. Luo, H. Z. Chen, Y. Q. Wu, W. W. Chen, Y. K. Song, W. Huang and Q. H. Yao, J. Agro-Environ. Sci., 2015, 34(4), 695-701.

48 L. Y. Liu, J. F. Tu, W. X. Qiu, W. W. Chen, J. Chen, Y. Q. Wu, Z. C. Huang and D. Q. Xue, J. Northwest Univ., 2016, 44(12), 99-106.

49 T. Y. Wang, G. H. Zhou, B. B. Sun, L. He, D. M. Zeng, Y. D. Chen and R. Ye, Rock Miner. Anal., 2016, 35(3), 295-301.

50 A. R. Zota, L. A. Schaider, A. S. Ettinger, R. O. Wright, J. P. Shine and J. D. Spengler, J. Expo. Sci. Environ. Epidemiol., 2011, 21, 495-505. 